\title{
Molecular Imaging Approaches for Supplemental Screening in Women at Increased Breast Cancer Risk
}

\author{
Amy M. Fowler \\ Department of Radiology, University of Wisconsin School of Medicine and Public Health, Madison, Wisconsin
}

$\mathbf{M}$ ammography is an effective screening method that reduces breast cancer mortality (1). However, mammography is not a perfect test and its sensitivity is diminished in women with dense breast tissue (2). For women at increased breast cancer risk, the use of imaging modalities in addition to mammography, termed supplemental screening, can improve the overall cancer detection rate. Current guidelines recommend MRI for supplemental screening in women with greater than $20 \%$ lifetime risk of breast cancer (3). For women who cannot tolerate MRI, have mammographically dense breast tissue, or have an intermediate lifetime risk of breast cancer, screening ultrasound can be considered (3). However, these techniques have some drawbacks, which have fueled interest in alternative functional imaging-based methods for supplemental screening in high-risk women. In this issue of The Journal of Nuclear Medicine, Brem et al. investigate the diagnostic performance of a molecular imaging approach for supplemental breast cancer screening (4).

\section{See page 678}

Breast-specific $\gamma$-imaging (BSGI) is a Food and Drug Administrationapproved radionuclide-based technique that can be used to detect breast cancer $(5,6)$. A high-spatial-resolution, small-field-of-view $\gamma$-camera detects and localizes $\gamma$-ray energy emitted by the radiopharmaceutical ${ }^{99 \mathrm{~m}} \mathrm{Tc}-\mathrm{methoxy}$ isobutylisonitrile (sestamibi), which preferentially accumulates in malignant breast cells with increased vascular supply and concentration of mitochondria compared with surrounding normal breast tissue. Images are acquired immediately after intravenous injection of the radiopharmaceutical, with the patient seated in standard mammographic views (craniocaudal and mediolateral oblique views) with the breast in mild compression for a total of approximately $40 \mathrm{~min}$. Interpretation of breast-specific $\gamma$-images follows a standardized lexicon and results in assessment categories and recommendations that parallel those of other imaging modalities outlined by the American

\footnotetext{
Received Jan. 24, 2016; revision accepted Jan. 26, 2016.

For correspondence or reprints contact: Amy M. Fowler, Department of Radiology, University of Wisconsin School of Medicine and Public Health, 600 Highland Ave., Madison, WI 53792-3252.

E-mail: afowler@uwhealth.org

Published online Feb. 9, 2016

COPYRIGHT (c) 2016 by the Society of Nuclear Medicine and Molecular Imaging, Inc.

DOI: $10.2967 /$ jnumed.115.171330
}

College of Radiology Breast Imaging-Reporting and Data System (BI-RADS) (7-9).

Although several studies have evaluated the performance of BSGI for diagnosing breast cancer in a heterogeneous mix of clinical indications (10), data regarding the application of BSGI for supplemental screening for women at increased breast cancer risk are sparse. The study by Brem et al. is a single-institution, retrospective review of asymptomatic, increased-risk women undergoing BSGI from 2010 to 2014 whose most recent screening mammogram showed no suspicious abnormalities (4). The study population consisted of 849 women ranging in age from 26 to $83 \mathrm{y}$ with a personal history of treated breast cancer, a family history of breast cancer, a personal history of an atypical or high-risk breast biopsy result, or a known genetic predisposition to breast cancer development. BSGI detected 14 mammographically occult cancers in 849 women, resulting in a supplemental cancer detection rate of 16.5 per 1,000 women screened. Furthermore, mammographic breast density did not affect BSGI's diagnostic performance; BSGI identified 11 cancers in 547 women with dense breast tissue and 3 cancers in 302 women with nondense breast tissue, which was not statistically different.

Brem et al. showed that the magnitude of increase in cancer detection rate when BSGI is added to screening mammography for high-risk women is comparable to that reported for screening breast MRI (4). A substudy of the American College of Radiology Imaging Network (ACRIN) 6666 trial demonstrated a supplemental cancer yield of 18.0 per 1,000 women screened with both MRI and mammography compared with mammography alone after 3 rounds of annual mammography and ultrasound screening (11). For comparison, supplemental cancer yield for screening breast ultrasound ranges from 1.9 to 4.4 per 1,000 women screened (12-14) and from 1.2 to 2.8 for digital breast tomosynthesis (15-18). Thus, functional breast imaging approaches, including MRI and BSGI, as adjunct screening modalities outperform the anatomic-based tools of ultrasound and tomosynthesis.

Another important parameter to consider besides the cancer detection rate when evaluating a new screening technique is the positive predictive value (PPV). Positive predictive value one $\left(\mathrm{PPV}_{1}\right)$ is the number of malignancies (true-positives) divided by the number of positive screening examinations and was $6.7 \%$ (14/212) for BSGI in the study by Brem et al. (4). $\mathrm{PPV}_{3}$ (biopsy performed) was $14.4 \%$ (14/97) and corresponds to the number of malignancies divided by the number of biopsies performed. Fibrocystic change, benign breast tissue, cyst contents, and fibroadenoma accounted for the falsepositive BSGI examinations, which decreases PPV. For comparison, the $\mathrm{PPV}_{1}$ and $\mathrm{PPV}_{3}$ for the ACRIN 6666 substudy were 
$8.4 \%$ and $25.4 \%$, respectively, for breast MRI, and the BI-RADS atlas recommends a practice audit benchmark range for $\mathrm{PPV}_{3}$ between $20 \%$ and $50 \%(7,11)$. Thus, PPVs for supplemental screening using BSGI are slightly lower than the reported values for MRI despite similar cancer detection rates.

A clinically useful breast cancer screening tool should be able to identify biologically significant cancers at a size smaller than would be detected by palpation and before spread to axillary lymph nodes. In the study by Brem et al., greater than half of the cancers detected by screening BSGI were small $(\leq 1 \mathrm{~cm})$ invasive carcinomas or ductal carcinoma in situ (4). Furthermore, most $(5 / 6 ; 83.3 \%)$ of the invasive carcinomas identified were histologic grade 2 and 3 with 2 triple-negative cancers and 1 cancer positive for human epidermal growth factor receptor 2 gene amplification. These results suggest that functional imaging through screening BSGI can identify clinically important cancers that are most likely to affect patient survival.

Despite a strong diagnostic performance of BSGI, concerns regarding lifetime radiation exposure will likely impede its widespread adoption as a serial supplemental screening method (3). Doses of 99m Tc-sestamibi reported by Brem et al. initially ranged from 592 to $1,188 \mathrm{MBq}$ (16.0 to $32.1 \mathrm{mCi}$ ), which is the Food and Drug Administration label-recommended dose, during the first $2 \mathrm{y}$ of the study and then were reduced to approximately $259-500 \mathrm{MBq}(7-13.5 \mathrm{mCi})$ during the last $2 \mathrm{y}$ (4). The reduction in administered activity did not adversely affect image quality and did not have a statistically significant effect on the cancer detection rate. The resulting whole-body effective dose equivalent of the standard-dose examinations ranges from 5.9 to $9.4 \mathrm{mSv}$, which decreases to approximately $2.4 \mathrm{mSv}$ for the low-dose examinations $(19,20)$. For comparison, the effective dose equivalent of digital mammography is approximately $0.44 \mathrm{mSv}$ and 1.2 $\mathrm{mSv}$ for digital mammography combined with tomosynthesis (19). Technologic improvements in instrumentation design combined with optimized patient preparation to increase radiopharmaceutical uptake have been pursued to reduce the radiation exposure to levels feasible to consider for breast cancer screening programs (20-23). Continued research into dose reduction methods or consideration of less frequent screening intervals will facilitate broader acceptance of radionuclidebased supplemental screening approaches in clinical practice.

Interest in applying functional imaging techniques for supplemental breast cancer screening continues to grow. This is in part due to the increasing recognition of the importance of individual formal risk assessments and establishment of dedicated specialty clinics, which advise high-risk women regarding screening strategies and riskreducing interventions. Furthermore, there are an expanding number of states with legislation on breast density driven by patient advocacy group concern regarding the limited sensitivity of mammography in women with dense breasts. The work reported by Brem et al. in this issue, as well as other recently published studies, are important to ensure that clinical use of supplemental screening approaches continue to be evidence-based $(4,20)$. Determination of the best supplemental screening tool will likely require direct comparison of the cancer detection rate, recall rate, and number of false-positive examinations in large, prospective multiinstitutional trials and include additional considerations such as radiation dose, cost, and accessibility.

\section{DISCLOSURE}

No potential conflict of interest relevant to this article was reported.

\section{REFERENCES}

1. Smith RA, Duffy SW, Gabe R, Tabar L, Yen AM, Chen TH. The randomized trials of breast cancer screening: what have we learned? Radiol Clin North Am. 2004;42:793-806.

2. Rosenberg RD, Hunt WC, Williamson MR, et al. Effects of age, breast density, ethnicity, and estrogen replacement therapy on screening mammographic sensitivity and cancer stage at diagnosis: review of 183,134 screening mammograms in Albuquerque, New Mexico. Radiology. 1998;209:511-518.

3. Mainiero MB, Lourenco A, Mahoney MC, et al. ACR appropriateness criteria breast cancer screening. J Am Coll Radiol. 2013;10:11-14.

4. Brem RF, Ruda RC, Yang JL, Coffey CM, Rapelyea JA. Breast-specific $\gamma$-imaging for the detection of mammographically occult breast cancer in women at increased risk. J Nucl Med. 2016;57:678-684.

5. Goldsmith SJ, Parsons W, Guiberteau MJ, et al. SNM practice guideline for breast scintigraphy with breast-specific gamma-cameras 1.0. J Nucl Med Technol. 2010;38:219-224.

6. Fowler AM. A molecular approach to breast imaging. J Nucl Med. 2014;55: $177-180$.

7. D'Orsi CJ, Sickles EA, Mendelson EB, Morris EA. ACR BI-RADS® Atlas, Breast Imaging Reporting and Data System. 5th ed. Reston, VA: American College of Radiology; 2013.

8. Conners AL, Hruska CB, Tortorelli CL, et al. Lexicon for standardized interpretation of gamma camera molecular breast imaging: observer agreement and diagnostic accuracy. Eur J Nucl Med Mol Imaging. 2012;39:971-982.

9. Conners AL, Maxwell RW, Tortorelli CL, et al. Gamma camera breast imaging lexicon. AJR. 2012;199:W767-W774.

10. Sun Y, Wei W, Yang HW, Liu JL. Clinical usefulness of breast-specific gamma imaging as an adjunct modality to mammography for diagnosis of breast cancer: a systemic review and meta-analysis. Eur J Nucl Med Mol Imaging. 2013;40: $450-463$.

11. Berg WA, Zhang Z, Lehrer D, et al. Detection of breast cancer with addition of annual screening ultrasound or a single screening MRI to mammography in women with elevated breast cancer risk. JAMA. 2012;307: 1394-1404.

12. Corsetti V, Ferrari A, Ghirardi M, et al. Role of ultrasonography in detecting mammographically occult breast carcinoma in women with dense breasts. Radiol Med (Torino). 2006;111:440-448.

13. Berg WA, Blume JD, Cormack JB, et al. Combined screening with ultrasound and mammography vs mammography alone in women at elevated risk of breast cancer. JAMA. 2008;299:2151-2163.

14. Brem RF, Tabar L, Duffy SW, et al. Assessing improvement in detection of breast cancer with three-dimensional automated breast US in women with dense breast tissue: the SomoInsight Study. Radiology. 2015;274:663-673.

15. Skaane P, Bandos AI, Gullien R, et al. Comparison of digital mammography alone and digital mammography plus tomosynthesis in a population-based screening program. Radiology. 2013;267:47-56.

16. Ciatto S, Houssami N, Bernardi D, et al. Integration of 3D digital mammography with tomosynthesis for population breast-cancer screening (STORM): a prospective comparison study. Lancet Oncol. 2013;14:583-589.

17. Rose SL, Tidwell AL, Bujnoch LJ, Kushwaha AC, Nordmann AS, Sexton R Jr. Implementation of breast tomosynthesis in a routine screening practice: an observational study. AJR. 2013;200:1401-1408.

18. Friedewald SM, Rafferty EA, Rose SL, et al. Breast cancer screening using tomosynthesis in combination with digital mammography. JAMA. 2014;311: 2499-2507.

19. Hendrick RE. Radiation doses and cancer risks from breast imaging studies. Radiology. 2010;257:246-253.

20. Rhodes DJ, Hruska CB, Conners AL, et al. Journal club: molecular breast imaging at reduced radiation dose for supplemental screening in mammographically dense breasts. AJR. 2015;204:241-251.

21. O'Connor MK, Hruska CB, Tran TD, et al. Factors influencing the uptake of ${ }^{99 m}$ Tc-sestamibi in breast tissue on molecular breast imaging. J Nucl Med Technol. 2015;43:13-20.

22. Hruska CB, Phillips SW, Whaley DH, Rhodes DJ, O'Connor MK. Molecular breast imaging: use of a dual-head dedicated gamma camera to detect small breast tumors. AJR. 2008;191:1805-1815.

23. Rhodes DJ, Hruska CB, Phillips SW, Whaley DH, O'Connor MK. Dedicated dual-head gamma imaging for breast cancer screening in women with mammographically dense breasts. Radiology. 2011;258:106-118. 